\title{
Triangular Human Capital Flows between Sending, Entrepot and the Rest of the World Regions
}

\author{
Don J. DeVoretz \\ RIIM, Simon Fraser University \\ Burnaby, B.C. Canada \\ John Ma \\ Division of Social Sciences \\ Hong Kong University of Science and Technology
}

\begin{abstract}
A model of triangular movement of highly skilled immigrants between a sending country (China/India) to an entrepot country (Canada) and then possibly to the rest of the world is developed. The question of who stays or leaves after arrival in the entrepot country is considered. The acquisition of subsidized human capital and the ascension to citizenship by immigrants are argued to be key conditioners that reduce the probability of staying in the entrepot country. Finally, the model predicts if the best or the mediocre highly skilled stay or leave the entrepot country for the sending region or the rest of the world.
\end{abstract}

Keywords: Human capital, brain drain, immigration 
Don J. DeVoretz and John Ma

\section{Résumé}

A model of triangular movement of highly skilled immigrants between a sending country (China/India) to an entrepot country (Canada) and then possibly to the rest of the world is developed. The question of who stays or leaves after arrival in the entrepot country is considered. The acquisition of subsidized human capital and the ascension to citizenship by immigrants are argued to be key conditioners that reduce the probability of staying in the entrepot country. Finally, the model predicts if the best or the mediocre highly skilled stay or leave the entrepot country for the sending region or the rest of the world.

Keywords: Human capital, brain drain, immigration

\section{Introduction}

In the 1990's a debate remerged over the size and duration of Canada's "brain drain", especially the transfer of human capital to the United States (DeVoretz and Laryea, 1998, Helliwell, 1999 and Wagner, 2000). In a similar vein, D. Zweig (1997) documented the economic and political motives for highly skilled Chinese émigrés to remain in the United States. Similar bilateral studies have been conducted to detect the size, duration and motivation for the movement of the highly skilled between Europe and the rest of the world. (Ward and Kunze, 2001 and Winkleman, 2001). Implicitly what we see emerging from this literature is a set of parallel studies assessing the effects of bilateral human capital transfers on both the sending and receiving regions and the individual movers. This paper proposes a new research tactic when it eschews the standard bilateral analysis and argues that human capital transfers are part of a general global system which transfers human capital from sending countries such as India-China (including Hong-Kong) to entrepot countries (Canada and Europe), and then on to the rest of the world (USA). ${ }^{1}$

In particular, we argue that Canada is an excellent entrepot example, given its unique immigration and integration policies and its strategic geographical location. ${ }^{2}$ An entrepot country in this context is defined as an intermediate destination country, which also confers subsidized benefits on recent immigrant arrivals. In turn, these immigrants arrivals, who may later return to their source country, or stay in their original entrepot destination country or move to a third destination (R.O.W.). ${ }^{3}$ Major issues arise in the Canadian or entrepot context from this complex trilateral movement of the highly skilled. For example, is 
Triangular Human Capital Flows between Sending, Entrepot and the Rest of the World Regions

Canada participating in a zero (or negative) sum game? In other words, do the immigrant arrivals from outside of North America to Canada just offset or not the loss of highly skilled Canadian émigrés to the United States and the ROW ${ }^{4}$

Moreover, do Canadian trained highly skilled leave as a consequence of competition from recent highly skilled arrivals ?50 the highly skilled immigrants that remain in Canada have an inferior (superior) skill set when compared to those immigrants who return or move on to the rest of the world? ${ }^{6}$ Furthermore, what are the roles respectively of the entrepot labor market and its immigration (emigration) policies in sorting the immigrants into stayers or movers after they arrive in the entrepot country? ${ }^{7}$

Implications of this human capital transfer on the sending region can also be profound, especially if the sending region is less developed (e.g. India-China). For example, how large is the taxpayer subsidy from the sending country to Canada? Furthermore, how long will it take before a reverse flow occurs from the entrepot country to the source country? Moreover, what fraction of the original leavers will return home and why? Are these leavers the most or least able of the highly skilled?

Finally will the rest of the world gain twice? In other words, will the initial Chinese (or Indian) highly skilled immigrants to the entrepot country (Canada/ EU) self-select and move on to the rest of the world, with the entrepot country's providing subsidized human capital (language training, etc)? Will these migrants to the rest of the world (USA) be more (or less) productive than those immigrants who remain in the entrepot (Canada) or return home (China)?

In order to draw explicit hypotheses from this stylized view of the world, we present figure 1, which schematically re-produces the potential movement pattern outlined above.

Figure 1. Triangular Human Capital Transfers:

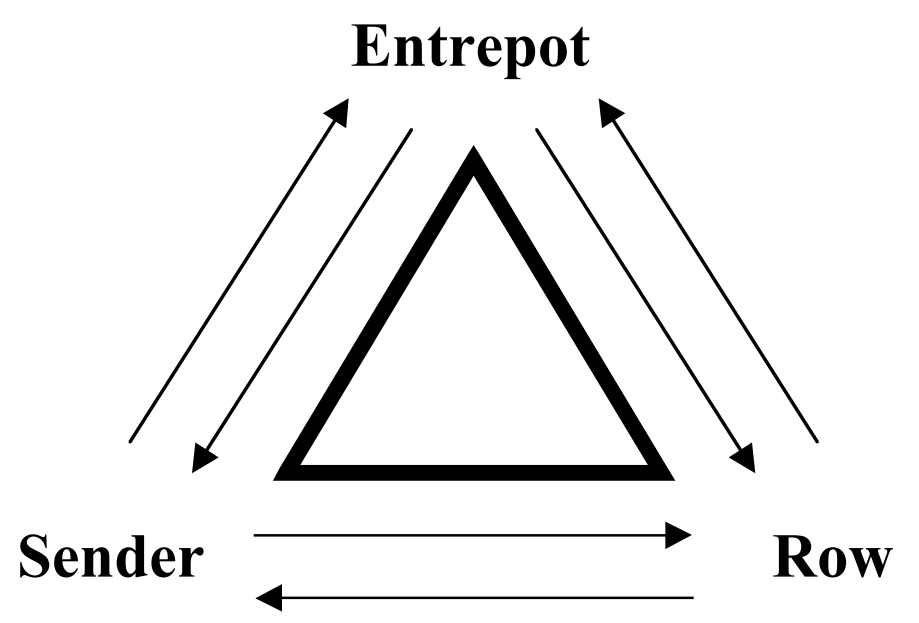


We argue that there initially exists three proto-typical sending regions, India, China, and Hong-Kong, and three possible receiving regions: an entrepot destination (Canada-Europe), the USA, and after a period of time abroad the home or the sending region.

Furthermore, we note that three options, or types of movement, exist for each emigrant after the initial move to the entrepot country over two separate periods in residence in the entrepot country. ${ }^{8}$ These options include staying in the new entrepot country (Canada), returning to the origin country, or moving on to a third country (ROW). In addition, multiple permutations of these types of immigrant movements can arise, and complex patterns appear which will now blur the traditional categories of temporary (less than one year) and permanent moves. Permutations of this three-stage movement become complex when multiple moves are considered. For example, the initial movement from the sending to entrepot country can next result in an onward move to the rest of the world, followed by a final move back to the original sending country. This example essentially describes Hong Kong emigres to Canada who originally came from the PRC and, after their stay in Canada, later returned to Hong Kong as Canadian citizens. They now are able to easily enter China, their original sending country, as Canadian citizens resident in Hong Kong.

In order to simplify the model, we initially start with two sending regions: IndiaChina, for the initial immigrant move, and the entrepot destinations either Canada or Europe. ${ }^{9}$ However, first we must recognize that the vast majority of highly trained people do not emigrate from the original sending region. Thus, a fundamental question we must answer is how does the sorting mechanism, which allocates stayers and leavers within the sending country, work? Moreover, what factors determine if the best of the highly skilled leave and the mediocre stay, or vice-versa? Moreover, if educated people do move from India or China to Canada is the impetus to leave Canada a result of immigrant acquiring subsidized complementary human capital at the entrepot destination ? The implication of this action would be that the brightest of the educated would be leaving since they have acquired further human capital. ${ }^{10}$

Given this two-stage investment behavior, a new series of questions arise in the entrepot destination. First, does this initial educational investment by the potential immigrant in the origin country arise due to a subsidy? Moreover, is strategic behavior involved? In other words, do people invest in a low educational cost (high tax) environment and move to higher educational cost but lower tax environments to improve their rate of return on their educational investment ? ${ }^{11}$ Clearly, an overlapping generations model can arise. In this case, for example, the progeny of Chinese immigrants to Canada and/or Europe can acquire their education in Canada or Europe and make their next move to either the SAR, PRC, or USA. Does this strategic behaviour, which is good for the individual, create public finance externalities which are bad for the state or taxpayer? ${ }^{12}$ 
Triangular Human Capital Flows between Sending, Entrepot and the Rest of the World Regions

Given these posed questions, the modelling process, which characterizes this trilateral flow, is best formulated in three stages. The first stage is to model who stays in the sending country and why. DeVoretz and Iturralde (2000) argue that demographic arguments, or the head of household's stage in the life cycle, condition the probability of staying for a highly skilled worker in a developed country. This is because the entrepot state by definition is the only state to confer subsidized public goods on highly skilled stayers differentially over their life cycle. For example, university education, health care, and subsidized daycare are all conferred on the household when the highly skilled head is middle aged with children. Epstein, et al., (1999) also argue that, in the context of a poor sending country, the probability of moving is a function of the state's (or Emperor's) willingness to confer benefits on or tax the highly skilled. In either a developed or less developed milieu, two additional questions must be posed and answered in the context of the model. At what stage in the life-cycle does the greatest (least) risk of staying (or leaving) occur and what noneconomic forces influence this decision to stay (leave) ? ${ }^{13}$

Once we model and determine who stays and who leaves the sending country, we must next model the motivation for immigrant's long-term behaviour after he/she initially arrives at the entrepot destination. Will the immigrant be a permanent resident in the original entrepot destination country, return to the sending country, or move on to the rest of the world (ROW)? Before we answer these questions we must ask why, after arrival in the entrepot destination, would anyone return to their origin country or move on to a third destination? On the surface, return migration appears to be a product of economic disappointment. However, the economics of this return decision are much more complex than an explanation based upon simple failure in the entrepot destination country. ${ }^{14}$ In a similar vein, it is initially difficult to rationalize onward migration to the ROW. In short, if the immigrant did not want to go to the original entrepot destination, why did he/she simply not initially move to the ultimate rest of the world (ROW) residence? ${ }^{15}$ Finally, what arguments best rationalize the behaviour of immigrants who follow sequential repeat patterns, first moving to the entrepot country, next returning to home (or ROW), and then repeating the process? ${ }^{16}$

As we earlier noted, we introduce several agents, an Emperor in the country of origin and two immigrant settlement agents in the entrepot country, to help us understand the process of initial, return, and on going immigrant movements. In short, we assert that each agent, in either the sending or entrepot country, dispenses gifts or services on a stayer or a potential mover which influences their decision to either stay, move on, or return to the original sending country. We outline the various agents' roles below in both the sending and entrepot countries. 
Don J. DeVoretz and John Ma

\section{Emperor and Emigrants}

As earlier stated Epstein et al.. (1999) argue that the role of the Emperor typically in the sending country - is to raise taxes, which in turn allows him to dispense favors to cliques within his society. These favored cliques in turn must lobby the Emperor to insure that they continue to receive these gifts from the Emperor and pay the minimum taxes for these benefits. This lobbying effort is both complex and expensive in two dimensions. First, time is involved in lobbying the Emperor for your presumed favors; and, secondly, the outcome from lobbying is often unknown. Additionally, the potential highly skilled émigré is heavily taxed by the Emperor to help finance the Emperor's gifts. ${ }^{17}$ It is quite possible under these circumstances that the total value of the gifts conferred on the population by the Emperor may be dissipated in lost output as his subjects lobby in lieu of productive activity. Under these conditions of uncertainty with respect to the outcome of your lobbying efforts and the simultaneous existence of differential time costs for lobbying across the potential émigré population, differential-lobbying efforts will emerge. For our skill group, namely highly trained and potentially mobile workers, their optimal amount of lobbying in the absence of mobility rights is unclear. If the highly skilled are rewarded according to their productivity in wages or salary in the empire and the Emperors taxes or sanctions varies, then the lobbying efforts on the potential emigres would depend on how effective these efforts would be in protecting their income. ${ }^{18}$ Regardless of their lobbying efforts and ultimate rewards, the highly skilled are still taxed. Now, if the Emperor introduces a mobility option, the highly skilled will leave if the Emperor's reward to the prospective émigré is less than their time cost of lobbying and taxes paid. ${ }^{19}$ This of course begs the question why the Emperor would ever permit the highly skilled to leave. We return to that question later, but simply note here that the omnipotent Emperor would only confer mobility rights to the resident highly skilled population if there exists a high enough probability of return migration by a sufficient number of the best of the highly skilled emigres. ${ }^{20}$

But the role of the Emperor in conditioning mobility does not stop here after the skilled subject has decided to emigrate or stay. The Emperor can control the exit conditions of his subjects and their return conditions. It is important to note that, in the actual case of China circa 2001, the government does not permit free mobility. You must gain permission to leave, which is either more or less lenient depending on the nature of travel. The Emperor's role in influencing the émigré after he leaves is crucial to understand, otherwise it would be difficult to rationalize why a successful émigré - as opposed to a failed émigré - would ever return to the Emperor's Kingdom. After all, the emigrant revealed his/her preference by leaving after her/his lobbying for benefits had failed. Thus, it would be difficult to rationalize why a successful émigré would decide to return to this environment without introducing an Emperor who later confers benefits or removes psychic costs on the returning ex-patriot. ${ }^{21}$ 
Triangular Human Capital Flows between Sending, Entrepot and the Rest of the World Regions

Essential to rationalizing any potential return emigration is a knowledge of the power of the Emperor to impose conditions on the potential returning émigré. The Emperor often imposes return conditions, which include some form of a surety bond. This bond can be in the form of money held in escrow by the Emperor. Indirect sanctions, which are tantamount to a surety bond, include the Emperor's bank discounting immigrant remittances when converted into local currency, or withholding exit visas for family residents still in the Empire. In a more positive manner, the Emperor can bribe the émigré to return with enhanced employment and social conditions after her return.

In sum, the Emperor's actions can condition who initially stays at home, who leaves the Kingdom, and who returns to the Kingdom after leaving. ${ }^{22}$

\section{Agents in the Entrepot Country}

After the move to the entrepot country, a second agent- a settlement workernow enters the decision process of the recent immigrant arrival to the entrepot country. After arrival the immigrant faces the decision to stay in the entrepot destination, return home, or move on to the rest of the world. Again the decision process is a nested one. First, after the highly skilled immigrant arrives, he/she must decide to stay or not at the end of each period. If the decision is to stay, then the immigration chain ends. However, when the immigrant is pushed out of the entrepot country by an unexpectedly bad labour experience, or is lured to the rest of the world by a higher return to the newly acquired human capital, the triangular movement continues to the third stage. In other words, the emigrant who has decided not to stay in the entrepot destination must now decide to return home or move on to the rest of the world (ROW) ${ }^{23}$ The actions of another agent, in this case the immigrant settlement worker in the entrepot country, will again influence if the émigré returns home or moves on to the rest of the world.

In fact, in the entrepot country two types, private and public, settlement workers appear. The private or volunteer settlement agent offers the recent arrival specific human capital, whilst a second government worker offers a public good with positive externalities in period 2 .

\section{Period One: Settlement Worker One}

After arrival, the recent immigrant is offered subsidized general human capital training (language, knowledge of labour market channels, cultural conventions) and specific human capital (programming skills, retraining for certification, and access to modern technology) by settlement worker one. The agent's goal in this case is to increase the probability of staying for the recent immigrant at the end of period one. ${ }^{24}$ As Borjas and Bratsberg (1996) have shown, acquisition of different types of specific human capital can increase the probability that a 
Don J. DeVoretz and John Ma

portion of the highly skilled immigrant arrivals will leave (or stay). Thus, this settlement worker's activity can perversely affect the staying probability and in addition may produce distributional consequences on the quality of those who stay and those who leave. As Borjas and Bratsberg (1996) argue, the best (or weakest) of the highly skilled immigrant arrivals may in turn, return home or move on to the rest of the world at the end of period one. The direction of the move, and the quality of the highly skilled sojourner, ultimately depend on the rates of return from the newly acquired human capital in the entrepot country. In sum, the settlement worker's activities in period one can increase (decrease) the probability of staying (leaving) for the best (or weakest) immigrant arrivals. Moreover, only one outcome in three (at end of period one), namely staying, is the preferred goal of the settlement agent. The other two outcomes are inferior for the settlement worker, but not necessarily for the potential émigré. In addition, the model predicts that only those types of human capital acquisition that enhance the rate of return in the entrepot country relative to the ROW or sending region will enhance the probability of staying in the entrepot country. ${ }^{25}$ Thus, in period one the greater the acquisition of agent provided specific (to Canada) human capital relative to the private acquisition of general (to the ROW) human capital acquisition the greater the probability of staying in the entrepot country. ${ }^{26}$

\section{Period Two: Settlement Worker Two}

If the newly arrived immigrant decides to remain in the entrepot destination at the end of period one, the second agent or settlement worker two enters and confers additional benefits. Again these benefits, which now arrive in the form of a public good, are intended to increase the probability of staying in the entrepot destination in subsequent periods. However, the benefits conferred may act perversely to induce the resident immigrant to leave. The main public good, which offers free rider benefits, is citizenship. If the immigrant remains in the entrepot country in period two and ascends to citizenship, then the immigrant's job opportunities rise and the mobility costs of moving to the rest of the world will fall. ${ }^{27}$ The free rider problem arises when erstwhile immigrants receive citizenship (and the accompanying passport) and the free mobility derived from the good behavior of older vintages of citizens in the entrepot country. The best example of this acquisition of a public good is the immigrant who receives citizenship in the entrepot country when his previous citizenship had limited mobility rights. For example a Chinese immigrant to Canada (or any EU member country) who eventually acquires entrepot citizenship is then free to travel to the United States (or to any EU member country). Now this sojourning émigré is free to exploit the specific human capital acquired in a subsidized manner in period one in the entrepot country, when heretofore they could not enter this third country. ${ }^{28}$ 
Triangular Human Capital Flows between Sending, Entrepot and the Rest of the World Regions

At this point in period two the Emperor in the original sending country can reappear and raise the costs of the entrepot immigrant's departure to the rest of the world in period two and influence the potential émigrés probability of returning home. If the Emperor cashes in the bond that is held at home, or more punitively revokes the emigrant's citizenship in the home country upon citizenship acquisition in the entrepot country, the probability of leaving for the rest of the world is reduced. A variation of this behavior arises when the entrepot country confers citizenship on the immigrant and requires that he/she renounce home country citizenship. Germany and USA currently do this, but Canada does not. The Emperor of course can induce return migration and deflect a potential move to the ROW by acting in a positive fashion and conferring unique benefits on the potential émigré after he/she acquires citizenship in the entrepot country and returns home. It is all a matter of which policy, punitive or benign, appears to be the most efficient mechanism a priori to the Emperor to induce return migration of the very highly skilled from the entrepot country.

In sum, the model at this stage can predict the probability of staying in the entrepot country and the perverse effects of incentives produced by the entrepot settlement workers providing human capital and public goods in periods one and two. Now any outcome in period two in the entrepot destination is possible, with either highly skilled or less skilled people staying or the best of the highly skilled returning home or moving on to the rest of the world as a consequence of these three agents' actions. What ultimately determines whether immigrants stay in the entrepot destination or move on is the rate of return of their acquired capital in the three settlement regions, actions of the Emperor and the immigrant's stage in the life cycle.

\section{Period three: Rest of the world and beyond}

A subset of the original leavers at end of period two may now have moved on to the rest of the world. This result may be Pareto optimal but may have distributional consequences on both the original sending country and the entrepot holding state. ${ }^{29}$ We review these outcomes below.

To deduce the number and quality of movers from the entrepot country to the ROW we must describe a stylized environment in the ROW. Foremost among the institutional conditions in the ROW is the resident tenure of the newly arrived émigré from the entrepot country. Two entry options are available - the immigrant may apply to use the permanent entry gate or the renewable (indefinitely) temporary entry gate. The former has a strict quota and the latter has no quota, so uncertainty of admission arises in the permanent entry gate. ${ }^{30}$ The permanent entry gate reproduces the environment in stage two for the immigrant in the entrepot country. The reward from the extra time spent waiting in the queue for permanent entry is the possible ascension to citizenship in the 
ROW destination. Temporary immigration to the ROW, on the other hand, may be of two types, with and without a queue. Citizenship in the entrepot country allows the highly skilled immigrant to move to ROW without waiting in a queue, thus lowering the cost of movement. ${ }^{31}$

The second important dimension in the ROW which conditions the type of émigré arrival from the entrepot country is the reward structure that the highly skilled émigré faces upon arrival. Since, by definition, the ROW confers no public goods on the émigré the ROW tax rates are low and less progressive than other destinations. The resulting income distribution under this tax regime is more unequal with a higher mean income and greater variance for any highly skilled occupation than the income distribution in the entrepot or sending countries.

In sum, the institutional setting of the ROW is a low tax environment with an unequal income distribution and a flexible but temporary immigrant entry point open uniquely to entrepot citizens. These pre-conditions will hasten the exodus of most highly skilled erstwhile entrepot immigrants.

One other feature of the ROW, its absolute size, manifests itself in several dimensions and is crucial to the analysis. The ROW economy (USA or EU) is absolutely large and hence this increases the probability of the émigré making a successful job match. ${ }^{32}$ Thus, in this expanded labour market an outstanding talent will have greater absolute chance of a successful job match, which exploits his/her unique, but outstanding skills. This scale effect, owing to an absolutely larger labour market, increases the probability of the most talented leaving the entrepot country for the ROW economy due to a higher probability of a successful job match.

In addition, the larger population in the ROW implies that the associated ethnic population will also be larger than in the entrepot country. This large ethnic population represents a potential social safety net that encourages the arrival of less talented, but still highly skilled, emigres from the entrepot country, since, if they fail in the mainstream labour market in the ROW, they can find employment in the large ethnic market.

In sum, if we assume that the potential pool of emigres from the entrepot destination to the ROW is risk neutral, both the number and quality distribution of the leavers can now be determined. At the first stage of residence in the entrepot country the highly skilled immigrant will only leave if their reservation wage in the entrepot country is at least matched by the expected income gain earned by moving to the ROW. ${ }^{33}$ The stylized facts reported by DeVoretz and Iturralde (2000) indicate that the population at risk of moving will be relatively young, small in size relative to the immigrant cohort in the entrepot country, and have an extensive prior mobility experience. ${ }^{34}$ Thus unattached, post-secondary school leavers, who are less than 35-years-old, will form the bulk of the émigré 
Triangular Human Capital Flows between Sending, Entrepot and the Rest of the World Regions

group. Given my earlier arguments about labour market scale and ethnic population size, this group will in turn be the most and least talented of the resident émigré pool in the entrepot country.

The public finance impact of émigrés on the ROW is unambiguous, since it receives immigrants embodied with other countries' taxpayer financed human capital. In turn by definition the ROW does not provide this generation of emigres any publicly financed goods - hence net tax receipts must rise in the ROW. The income distribution effect of the resident highly skilled in the ROW is however unclear. The wage impact derived from the arrival of both the best and least talented of the highly skilled who emigrate from the entrepot to the ROW can raise or lower the wage rate for the average highly skilled resident in the ROW, and perhaps eliminate bottle necks.

Finally, we can infer from these conditions in the ROW that the mediocre highly skilled and most risk-adverse of the potential emigres (middle-aged) will most likely remain in the entrepot destination. ${ }^{35}$

\section{Acknowledgements:}

Discussions with D. Coulombe, A. Kunze, M. Ward and K. Zhang improved this paper. IZA (Germany), RIIM (Vancouver) and Hong Kong University of Science and Technology supported this research piece. Excellent critical remarks by a referee also greatly improved the precision and exposition of the paper. Support from RIIM is gratefully acknowledged.

\section{End Notes:}

1. An entrepot country is one in which traditionally exported goods are held in storage to be re-exported at a later date. Thus, Singapore and Hong-Kong were traditional entrepot centres. In this context, an entrepot country is an immigrant receiving country which provides human capital to the immigrant before she/he emigrates.

2. McInnis (2001) argues persuasively that Canada's emigration experience in the last half of the $19^{\text {th }}$ century can be partially characterized by this entrepot model for its then $19^{\text {th }}$ century semi and skilled labour movement from Canada to the United States.

3. Canada is one particular example of an entrepot country. Other examples exist, namely Israel, Ireland, Germany, the United Kingdom and perhaps the entire European Union. 
Don J. DeVoretz and John Ma

4. Israel could be another zero sum case in point. Here Russian émigrés may be replacing Sabra (native-born) Israelis who have left for the rest of the world. A similar pattern may be emerging in the SAR or Hong Kong when Mainland Chinese engineers replace Hong Kong engineers in the SAR who have left for North America.

5. This general equilibrium effect is unlikely in reality since Canada's highly skilled immigration policy is predicated on the existence of positive excess demand for highly skilled in the Canadian economy. Empirical work by Akbar and DeVoretz (1993) confirms this assertion.

6. This model is capable of predicting the skill level of the movers and stayers if we visualize the state as a tax agent who provides services to its immigrant clients. Borrowing on the work of Epstein et. al (1999) as noted in the test if Emperor (or state) redistributes benefits away from the highly skilled and the lobbying costs are too high to recover these lost benefits then the highly skilled will leave. The cited work of DeVoretz and Itturalde (2000) with its stayer model empirically tests and confirms the existence of sorting in the Canadian context circa 1992-96.

7. As noted later, the ROW countries are characterized by the lack of agents. Since these states provide no services their tax rates are low and those emigrants who anticipate to realize incomes on the extreme right hand side of the distribution or the highly skilled will leave the entrepot country for the ROW. This argument is embedded in the Borjas and Bratsberg model (1996) and simply extended here.

8. This model needs at least two periods since agents in the entrepot destination country must equip the immigrant arrivals with human capital and offer a public good which will influence the immigrant's decision to stay or move on in the second period.

9. Clearly the potential immigrant from China-India could directly enter the United States. We ignore this option since we want to focus on the impact of immigration-emigration in the highly skilled context of an entrepot country such as Canada. In addition, the USA only has a modest entry gate for permanent highly skilled (E class visa) immigrants. Thus, in fact the USA is not the initial destination of the majority of highly skilled permanent Chinese immigrants.

10. Borjas and Bratsburg (1996) argue that only if the acquired human capital in the entrepot country is complementary to existing capital in the USA or the original sending region would the best leave. If the immigrant arrivals receive human capital in the entrepot countries which yields a higher return by staying (second language acquisition) then the brightest would stay in the entrepot country. 
Triangular Human Capital Flows between Sending, Entrepot and the Rest of the World Regions

11. Naïve economic theory would answer this question in the affirmative. However, transactions costs loom large in any move and they grow over the household's lifetime. Finally, people stay to access public goods in the high tax environment. Hence, the answer to the question is not at all obvious.

12. See Anderson and Konrad (2001). In particular, they explore the effect of increased mobility or globalization on the incentives to invest in human capital, with and without subsidies, and in the absence of an insurance scheme to forestall the impact of post-investment taxation on the returns to human capital.

13. By adapting the complete DeVoretz-Iturralde (2000) stayer model to this circulation model these questions can be answered.

14. This is the naïve explanation owing to the Neo-classical arguments of the 1980 's and earlier. Clearly, return migrants who have acquired complementary human capital in the entrepot country have not failed but are motivated to return by a higher reward in the original sending country.

15. As noted immigrant quotas prevent most highly skilled immigrants from directly entering either the USA or Hong Kong from China.

16. For a minority of Chinese immigrants to Canada this repeated movement has earned them the term astronauts.

17. In China, one of our selected countries, intellectuals and the highly trained have had, in the past, their privileges removed as they were banished to the countryside in the late 1960's. In the absence of immigration, their human capital and the country's output suffered. However, in the 1990's, intellectuals and other skilled workers (under some restrictions) are free to leave China.

18. Clearly if the required lobbying effort is small to successfully protect your job, this limited action will be carried out, and the individual will stay given the high costs of movement.

19. This condition holds for those potential emigres who are on the margin where mobility costs just equal gain from moving. These added costs imposed by the Emperor push the marginal highly skilled immigrants. See Epstein et al.. (1999) for a complete exposition of this point in the form of a formal proof. 
Don J. DeVoretz and John Ma

20. In order to offset the loss of productivity to the Empire from the permitted emigration, a sufficient number of immigrants must return with added training to offset the loss of those who remain. In this sense the best must return in sufficient numbers.

21. For example, upon return the conditions of extant family members may be improved by granting them benefits that they formally did not enjoy.

22. It should be remembered that an optimistic Emperor believed that mobility rights would allow the highly skilled to emigrate, gain skills in the entrepot country and then return with skills which would increase productivity in the Empire. This is all predicated on a sufficient number of return emigres from the entrepot to the sending country. When this optimism is not realized as in China circa 2002 the Emperor must resort to bribes.

23. Formally the decision as argued by DeVoretz and Iturralde (2000a) is that the reservation wage, which keeps the potential émigré in the entrepot country, is now exceeded by either (or both) the potential income gains in the ROW or sending country after the enhancement of human capital and the acquisition of entrepot citizenship in the entrepot country. If the immigrant does not gain human capital appropriate for the production functions in the ROW and/or the sending country but specific to the entrepot country, then the income gain from staying will exceed the gain from leaving. See DeVoretz and Itturalde (2000) for a more complete exposition of this condition.

24. The settlement worker by definition provides human capital to increase the productivity of all immigrant arrivals in the entrepot society and reduce the risk of return migration. Settlement workers may also have altruistic motives, namely to ease the immigrant's integration into society. However, in entrepot countries such as Australia, Canada, Germany, and especially Israel, government subsidies to private altruistic agencies is predicated on increasing the staying probability of the recent arrival and to increase the immigrant's contribution to the society. To this extent this governmental motive is not altruistic.

25. In the Canadian context human capital acquisition for the Canadian economy is the central investment made by the agent in period 1. Examples include: access to labour market information, validation of certificates, recognition of professional credentials and language training (English and French).

26. Thus, immigrants who enter post-secondary education to acquire a general (to the ROW) skill with little or no specific human capital acquisition from an agent in period 1 will be more apt to leave. 
Triangular Human Capital Flows between Sending, Entrepot and the Rest of the World Regions

27. The mobility costs for Chinese immigrants living in Canada without Canadian citizenship are the waiting and legal costs to obtain a permanent visa (E type) for the USA. These are considerable costs. With Canadian citizenship a NAFTA visa is obtained the same day as application with no lawyer required. Furthermore, there is no queue for this NAFTA visa and thus the probability of entry is certain if side conditions are met.

28. Both the European Union and Canada (or the United States) allow immigrants who acquire citizenship in their respective areas to enter into a merged labour market.

29. If there exist positive externalities from a country's brain drain as argued by Stark (1997) then the number of movers under a market solution would be sub-optimal. Obviously if there are negative externalities on production in the sending region from this movement as the traditional brain drain literature argued in the 1970's, then the free market solution is too large.

30. A variation of this tenure is temporary status with an overall quota and end date. The "green card ", or temporary highly skilled immigrant recruitment program in Germany, and the H1B temporary worker visa program in the United States, both are illustrations of this variation.

31. The temporary entry gate to the ROW with a queue is available to any entrepot immigrant (or any highly skilled immigrant in the world); however, the time cost plus legal fees are substantial. Thus, the existence of unique non-queue entry gate for entrepot immigrants (with entrepot citizenship) reduces the transactions costs and the time in queue. This will hasten the departure of those eligible to use this gate.

32. The ROW by definition is so large that even if it has a relative disadvantage in one or more skills relative to the entrepot country, the ROW will still have a larger labour market for that skill.

33. As DeVoretz and Iturralde (2001) have shown this is a small percentage of the stock of potential movers, approximately 5 to 20 per cent.

34. These conditions either increased the probable income gain from a move or lowered the mobility costs of movement. 
Don J. DeVoretz and John Ma

\section{References:}

Akbar, S. and D. DeVoretz. 1993. "Canada's demand for Third World immigrants to Canada: 1974-1986," World Development 21: 177-187.

D.Anderson, F. and K. Konrad. 2001. "Globalization and Human Capital Formation,” IZA Discussion Paper 245.

D.Anderson, F. and K. Konrad. 2001. "Human Capital Investment and Globalization in Extortionary States," IZA Discussion Paper 239.

Borjas, G. and Bratsberg, B. 1996. "Who leaves: The out-migration of the foreign-born," Review of Economics and Statistics 78: 165-76.

DeVoretz, D. and S. Laryea. 1998. "Human Capital Transfers: USA and Beyond,” RIIM Working Paper 98-18.

DeVoretz, D. and C. Itturalde. 2000a. "Probability of Staying in Canada," RIIM Working Paper 00-06.

DeVoretz, D. and C. Itturalde. 2000b. "Why do the highly skilled stay in Canada," Policy Options March: 59-63 .

Epstein, G.S., A.L. Hillman and D.H. Ursprung. 1999. "The king never emigrates," Review of Development Economics, 3: 107-121.

Helliwell, J. F. 1999. "Checking the brain drain: Evidence and implications," Policy Options, September: 6-17.

McInnis, M. 2001. The Anglo-Canadian Hemorrhage: The Great Canadian Emigration from Canada, 1861-1901, Paper presented at Canadian Historical Association, Laval University, May.

Stark, O., C. Helmenstien and A. Praskawetz. 1997. " A brain gain with a brain drain," Economic Letters 55: 227-34.

Wagner, D. 2000. "Do Tax Differences Contribute Toward the Brain Drain From Canada to the U.S.?," Ph.D. dissertation, University of British Columbia.

Ward, M. and A. Kunze.2001. International Mobility of Workers and Firms' Preparedness for the Global Markets. Paper presented at the International Mobility of Highly Skilled Worker's Workshop, IZA, Bonn, Germany, March. 
Triangular Human Capital Flows between Sending, Entrepot and the Rest of the World Regions

Winkleman, R. The IZA International Employer Survey 2000. Paper presented at _The International Mobility of Highly Skilled Workers Workshop, IZA, Bonn, Germany, March, 2001.

Zweig, D. 1997. "To return or not to return? Politics Vs. economics in China's brain drain," Studies in Comparative International Development 33(1): 92-125.

Received September 2001; Revised March 2002 
${ }^{3}$ Canada is one particular example of an entrepot country. Other examples exist, namely Israel, Ireland, Germany, the United Kingdom and perhaps the entire European Union.

${ }^{4}$ Israel could be another zero sum case in point. Here Russian émigrés may be replacing Sabra (native-born) Israelis who have left for the rest of the world. A similar pattern may be emerging in the SAR or Hong Kong when Mainland Chinese engineers replace Hong Kong engineers in the SAR who have left for North America.

${ }^{5}$ This general equilibrium effect is unlikely in reality since Canada's highly skilled immigration policy is predicated on the existence of positive excess demand for highly skilled in the Canadian economy. Empirical work by Akbar and DeVoretz (1993) confirms this assertion.

${ }^{6}$ This model is capable of predicting the skill level of the movers and stayers if we visualize the state as a tax agent who provides services to its immigrant clients. Borrowing on the work of Epstein et. al (1999) as noted in the test if Emperor (or state) redistributes benefits away from the highly skilled and the lobbying costs are too high to recover these lost benefits then the highly skilled will leave. The cited work of DeVoretz and Itturalde (2000) with its stayer model empirically tests and confirms the existence of sorting in the Canadian context circa 1992-96.

${ }^{7}$ As noted later, the ROW countries are characterized by the lack of agents. Since these states provide no services their tax rates are low and those emigrants who anticipate to realize incomes on the extreme right hand side of the distribution or the highly skilled will leave the entrepot country for the ROW. This argument is embedded in the Borjas and Bratsberg model (1996) and simply extended here.

${ }^{8}$ This model needs at least two periods since agents in the entrepot destination country must equip the immigrant arrivals with human capital and offer a public good which will influence the immigrant's decision to stay or move on in the second period.

${ }^{9}$ Clearly the potential immigrant from China-India could directly enter the United States. We ignore this option since we want to focus on the impact of immigration-emigration in the highly 
Triangular Human Capital Flows between Sending,

Entrepot and the Rest of the World Regions

skilled context of an entrepot country such as Canada. In addition, the USA only has a modest entry gate for permanent highly skilled (E class visa) immigrants. Thus, in fact the USA is not the initial destination of the majority of highly skilled permanent Chinese immigrants.

${ }^{10}$ Borjas and Bratsburg (1996) argue that only if the acquired human capital in the entrepot country is complementary to existing capital in the USA or the original sending region would the best leave. If the immigrant arrivals receive human capital in the entrepot countries which yields a higher return by staying (second language acquisition) then the brightest would stay in the entrepot country.

${ }^{11}$ Naiive economic theory would answer this question in the affirmative. However, transactions costs loom large in any move and they grow over the household's lifetime. Finally, people stay to access public goods in the high tax environment. Hence, the answer to the question is not at all obvious.

${ }^{12}$ See Anderson and Konrad (2001). In particular, they explore the effect of increased mobility or globalization on the incentives to invest in human capital, with and without subsidies, and in the absence of an insurance scheme to forestall the impact of postinvestment taxation on the returns to human capital.

${ }^{13}$ By adapting the complete DeVoretz-Iturralde (2000) stayer model to this circulation model these questions can be answered.

${ }^{14}$ This is the naïve explanation owing to the Neo-classical arguments of the 1980's and earlier. Clearly, return migrants who have acquired complementary human capital in the entrepot country have not failed but are motivated to return by a higher reward in the original sending country.

${ }^{15}$ As noted immigrant quotas prevent most highly skilled immigrants from directly entering either the USA or Hong Kong from China.

${ }^{16}$ For a minority of Chinese immigrants to Canada this repeated movement has earned them the term astronauts.

${ }^{17}$ In China, one of our selected countries, intellectuals and the highly trained have had, in the past, their privileges removed as they were banished to the countryside in the late 1960's. In the absence of immigration, their human capital and the country's 
output suffered. However, in the 1990's, intellectuals and other skilled workers (under some restrictions) are free to leave China.

${ }^{18}$ Clearly if the required lobbying effort is small to successfully protect your job, this limited action will be carried out, and the individual will stay given the high costs of movement.

${ }^{19}$ This condition holds for those potential emigres who are on the margin where mobility costs just equal gain from moving. These added costs imposed by the Emperor push the marginal highly skilled immigrants. See Epstein et al. (1999) for a complete exposition of this point in the form of a formal proof.

${ }^{20}$ In order to offset the loss of productivity to the Empire from the permitted emigration, a sufficient number of immigrants must return with added training to offset the loss of those who remain. In this sense the best must return in sufficient numbers.

${ }^{21}$ For example, upon return the conditions of extant family members may be improved by granting them benefits that they formally did not enjoy.

${ }^{22}$ It should be remembered that an optimistic Emperor believed that mobility rights would allow the highly skilled to emigrate, gain skills in the entrepot country and then return with skills which would increase productivity in the Empire. This is all predicated on a sufficient number of return emigres from the entrepot to the sending country. When this optimism is not realized as in China circa 2002 the Emperor must resort to bribes.

${ }^{23}$ Formally the decision as argued by DeVoretz and Iturralde (2000a) is that the reservation wage, which keeps the potential émigré in the entrepot country, is now exceeded by either (or both) the potential income gains in the ROW or sending country after the enhancement of human capital and the acquisition of entrepot citizenship in the entrepot country. If the immigrant does not gain human capital appropriate for the production functions in the ROW and/or the sending country but specific to the entrepot country, then the income gain from staying will exceed the gain from leaving. See DeVoretz and Itturalde (2000) for a more complete exposition of this condition.

${ }^{24}$ The settlement worker by definition provides human capital to increase the productivity of all immigrant arrivals in the entrepot society and reduce the risk of return migration. Settlement workers 
Triangular Human Capital Flows between Sending,

Entrepot and the Rest of the World Regions

may also have altruistic motives, namely to ease the immigrant's integration into society. However, in entrepot countries such as Australia, Canada, Germany, and especially Israel, government subsidies to private altruistic agencies is predicated on increasing the staying probability of the recent arrival and to increase the immigrant's contribution to the society. To this extent this governmental motive is not altruistic.

${ }^{25}$ In the Canadian context human capital acquisition for the Canadian economy is the central investment made by the agent in period 1. Examples include: access to labour market information, validation of certificates, recognition of professional credentials and language training (English and French).

${ }^{26}$ Thus, immigrants who enter post-secondary education to acquire a general (to the ROW) skill with little or no specific human capital acquisition from an agent in period 1 will be more apt to leave.

${ }^{27}$ The mobility costs for Chinese immigrants living in Canada without Canadian citizenship are the waiting and legal costs to obtain a permanent visa (E type) for the USA. These are considerable costs. With Canadian citizenship a NAFTA visa is obtained the same day as application with no lawyer required. Furthermore, there is no queue for this NAFTA visa and thus the probability of entry is certain if side conditions are met.

${ }^{28}$ Both the European Union and Canada (or the United States) allow immigrants who acquire citizenship in their respective areas to enter into a merged labour market.

${ }^{29}$ If there exist positive externalities from a country's brain drain as argued by Stark (1997) then the number of movers under a market solution would be sub-optimal. Obviously if there are negative externalities on production in the sending region from this movement as the traditional brain drain literature argued in the 1970 's, then the free market solution is too large.

30 A variation of this tenure is temporary status with an overall quota and end date. The "green card ", or temporary highly skilled immigrant recruitment program in Germany, and the H1B temporary worker visa program in the United States, both are illustrations of this variation. 
${ }^{31}$ The temporary entry gate to the ROW with a queue is available to any entrepot immigrant (or any highly skilled immigrant in the world); however, the time cost plus legal fees are substantial. Thus, the existence of unique non-queue entry gate for entrepot immigrants (with entrepot citizenship) reduces the transactions costs and the time in queue. This will hasten the departure of those eligible to use this gate.

32 The ROW by definition is so large that even if it has a relative disadvantage in one or more skills relative to the entrepot country, the ROW will still have a larger labour market for that skill.

${ }^{33}$ As DeVoretz and Iturralde (2001) have shown this is a small percentage of the stock of potential movers, approximately 5 to 20 per cent.

34 These conditions either increased the probable income gain from a move or lowered the mobility costs of movement. 